\title{
Liquid Chromatographic Determination of Plasma Ropivacaine for Assessing Pharmacokinetics of the Viscous Preparation
}

\author{
Takeshi Kawata,${ }^{a, b}$ Masato Homma, ${ }^{*, a, c}$ Yoshihiro Kakiuchi,${ }^{c}$ Shinichi Inomata, ${ }^{d}$ Masayuki Miyabe, ${ }^{d}$ \\ Daisuke KовауаSні, ${ }^{b}$ Yasunori Morimoto, ${ }^{b}$ and Yukinao KонDA ${ }^{a, c}$ \\ ${ }^{a}$ Department of Pharmaceutical Sciences, Graduate School of Comprehensive Human Sciences, University of Tsukuba; \\ 1-1-1 Ten-nodai, Tsukuba, Ibaraki 305-8575, Japan: ${ }^{b}$ Faculty of Pharmaceutical Sciences, Josai University; 1-1 \\ Keyakidai, Sakado, Saitama 350-0295, Japan: ${ }^{c}$ Department of Pharmacy, Tsukuba University Hospital; 2-1-1 Amakubo, \\ Tsukuba, Ibaraki 305-8576, Japan: and ${ }^{d}$ Department of Anesthesiology, Graduate School of Comprehensive Human \\ Sciences, University of Tsukuba; 1-1-1 Ten-nodai, Tsukuba, Ibaraki 305-8575, Japan.
}

Received July 15, 2005; accepted October 4, 2005; published online October 5, 2005

We developed assay method for determination of plasma ropivacaine by using reversed-phase high performance liquid chromatography (HPLC) equipped with ordinary octadecylsilyl silica-gel (ODS) column. Plasma samples spiked with internal standard (bupivacaine) were treated by ethylacetate to extract ropivacaine and internal standard. The ropivacaine and internal standard separated on ODS column were detected by an ultra violet (UV) detector set at $215 \mathrm{~nm}$. The mobile phase solvent consisted of acetonitrile, methanol and $0.05 \mathrm{~m}$ phosphate buffer adjusted to $\mathrm{pH} 4.0(10: 30: 60, \mathrm{v} / \mathrm{v})$ was pumped at a flow rate of $0.8 \mathrm{ml} / \mathrm{min}$. The calibration curve of ropivacaine was linear at the concentration of $25-1000 \mathrm{ng} / \mathrm{ml}(r=0.9998)$. The recoveries of ropivacaine from plasma were greater than $87.9 \%$ with the coefficient of variations $(\mathrm{CVs})$ less than $6.1 \%$. The CVs for intra- and inter-day assay of ropivacaine were $2.0-12.0 \%$ and $1.7-14.8 \%$, respectively. This HPLC method was applied to determining plasma ropivacaine in two healthy subjects after receiving $0.5 \%$ ropivacaine viscous preparation, which was prepared in our hospital. Our preliminary pharmacokinetic data showed that ropivacaine viscous could be used safely based on the plasma ropivacaine concentrations $\left(C_{\max }: 89-125 \mathrm{ng} / \mathrm{ml}\right)$ for pain relief in oral mucosa.

Key words ropivacaine; viscous preparation; high performance liquid chromatography; pharmacokinetics

Ropivacaine, an aminoamide derivative, is used for local anesthetic agent as well as lidocaine, bupivacaine and mepivacaine (Fig. 1) ${ }^{1,2)}$ Unlike bupivacaine and mepivacaine, which are racemic mixtures of the enantiomers containing equal proportion of the $(S)$ and $(R)$ forms, ropivacaine is exclusively the $(S)$-enantiomer. ${ }^{2,3)}$ Since the $(R)$-enantiomer in the racemic aminoamide has known to be toxic, ${ }^{2,3)}$ ropivacaine potentially provides lower toxicity on heart and central nervous system compared with bupivacaine and mepivacaine. ${ }^{2,4-8)}$ Ropivacaine has an advantage over lidocaine in the drug metabolism. Lidocaine produces the toxic metabolites, monoethyl-glycinexylidide and glycinexylidide, in its hepatic metabolism, which are circulating with higher concentration in blood. ${ }^{9}$ On the other hand, blood concentrations of ropivacaine metabolites, 3-hydroxy-ropivacaine and 2-hydroxy-methyl-ropivacaine, have known to be very low (undetectable levels), even though they are pharmacologically active. ${ }^{10,11)}$ These characteristics of ropivacaine may be suitable
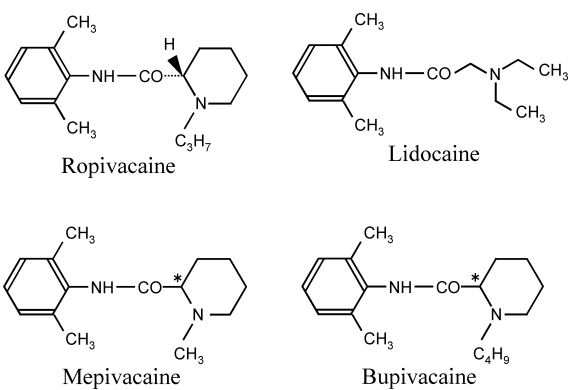

Fig. 1. Chemical Structures of Ropivacaine, Lidocaine, Mepivacaine and Bupivacaine

Bupivacaine was used as an internal standard for this assay. *: Asymmetric carbon. for the viscous preparation used for pain relief in oral cancer patients, because the patients sometimes swallow the viscous preparation accidentally. To assess the safety of ropivacaine viscous, we firstly need to determine the plasma ropivacaine concentration when applied to oral mucosa.

The reported HPLC method for measuring plasma ropivacaine employed solid-phase extraction ${ }^{12,13)}$ and $\mathrm{C}_{8}$ column, ${ }^{12,14)} \mathrm{CN}$ column ${ }^{15)}$ or column switching technique ${ }^{16)}$ for the separation. We developed a rapid and sensitive method for quantitating plasma ropivacaine by combined use of ODS column and liquid-liquid extraction with ethylacetate.

\section{MATERIALS AND METHODS}

Chemicals and Instruments Ropivacaine hydrochloride and its injective product were kindly supplied by AstraZeneca (London, U.K.). Bupivacaine hydrochloride was used as an internal standard (IS), which was purchased from Sigma Chemical Co. (St. Louis, MO, U.S.A.). Acetonitrile and methanol were of HPLC grade purchased from Wako Pure Chemical Industries, Ltd. (Osaka, Japan). Carmellose sodium used for viscous preparation was purchased from Maruishi Pharmaceutical, Co., Ltd. (Osaka, Japan). All other chemicals were of HPLC or analytical reagent grade.

Preparation of Standard Solutions The control plasma was prepared by using an alternative human plasma (Twinconsera H, Nissui Pharmaceutical Co., Ltd., Tokyo, Japan). Standard solution of ropivacaine hydrochloride was prepared by diluting the stock solution with human plasma to make the concentration of $25,50,100,250,500$ and $1000 \mathrm{ng} / \mathrm{ml}$ and stored at $-20^{\circ} \mathrm{C}$ until use. The IS was prepared as the $10 \mu \mathrm{g} / \mathrm{ml}$ solution in distilled water and stored at $4{ }^{\circ} \mathrm{C}$. 
Preparation of Ropivacaine Viscous Ropivacaine viscous $(0.5 \%)$ was prepared by using $1.88 \mathrm{~g}$ of carmellose sodium, $50 \mathrm{ml}$ of ropivacaine $(10 \mathrm{mg} / \mathrm{ml})$, and a proper quantity of distilled water. The concentration of ropivacaine is 4 times lower than that of lidocaine viscous $(2 \%)$, because the anesthetic activity of ropivacaine is known to be 4 times strong compared with lidocaine. $\left.{ }^{1,2}\right)$ The viscosity of the ropivacaine viscous measured by spindle type of rotational viscometer (KN3312482, TokyoKeiki, Tokyo, Japan), was $2150 \pm 50$ centipoise (C.P.), which was somewhat higher degree of viscosity compared with lidocaine viscous (1850 \pm 50 C.P.). This value is suitable for viscous preparation in adhering the drug to oral mucosa.

HPLC Apparatus and Analytical Conditions HPLC system used for present study consisted of a pump (CCPD, TOSOH, Tokyo, Japan), an UV detector (UV-8010, TOSOH) and an integrator (C-R4A, Shimadzu, Kyoto, Japan). ODS column (TSK-GEL, 4.6 i.d. $\times 150 \mathrm{~mm}$, TOSOH) as the analytical column was maintained at ambient temperature. The detection wavelength was set at $215 \mathrm{~nm}$. The mobile phase solvent consisted of acetonitrile, methanol and $0.05 \mathrm{~m}$ phosphate buffer adjusted to $\mathrm{pH} 4.0(10: 30: 60, \mathrm{v} / \mathrm{v})$ was pumped at a flow rate of $0.8 \mathrm{ml} / \mathrm{min}$.

Assay Procedures To $500 \mu \mathrm{l}$ plasma sample in a $10 \mathrm{ml}$ siliconized test tube, $100 \mu \mathrm{l}$ IS solution $(10 \mu \mathrm{g} / \mathrm{ml})$ and $250 \mu \mathrm{l} 0.1 \mathrm{M}$ sodium hydroxide were added. After agitating the mixture, plasma sample was treated by $2 \mathrm{ml}$ ethylacetate to extract ropivacaine and IS. The mixture was agitated for $1.5 \mathrm{~min}$ and was centrifuged at $1500 \boldsymbol{g}$ for $6 \mathrm{~min}$. The upper organic phase was transferred to another tube, and then the plasma sample was treated by further $2 \mathrm{ml}$ ethylacetate. The upper organic phase was transferred to the tube again. The combined organic phase was evaporated to dryness under a stream of nitrogen at $40^{\circ} \mathrm{C}$. The residue was dissolved in $100 \mu \mathrm{l}$ of the mobile phase solvent and the $25 \mu \mathrm{l}$ aliquot were injected into the HPLC column.

Application of Ropivacaine Viscous to Healthy Volunteers Two healthy male volunteers were enrolled for this study. The volunteers held $5 \mathrm{ml}$ of $0.5 \%$ ropivacaine viscous in their mouths for $10 \mathrm{~min}$ and then, put out the drug from their mouths. Blood samples were collected before and 10, $20,40,60,90,120,180$ and 240 min after viscous administration. Informed consent was obtained from each subject, and the study was approved by The Ethical Committee of the University of Tsukuba.

Pharmacokinetic parameters (maximum drug concentration; $C_{\max }$, maximum drug concentration time; $T_{\max }$, area under the blood concentration time curve; $A U C$, half-life; $t_{1 / 2}$ and mean residence time; $M R T$ ) of ropivacaine was calculated by WinNonlin Standard (Pharsight Corporation, Mountain View, CA, U.S.A.).

\section{RESULTS}

Typical chromatograms for the blank plasma and the plasma spiked with ropivacaine and IS were shown in Fig. 2. The peaks representing ropivacaine and IS were observed at the retention times of 8.4 and $13.8 \mathrm{~min}$, respectively. Although there was minor interfering peak at the position of ropivacaine, the effects on routine determination of plasma ropivacaine was negligible. The detection limit of ropiva-

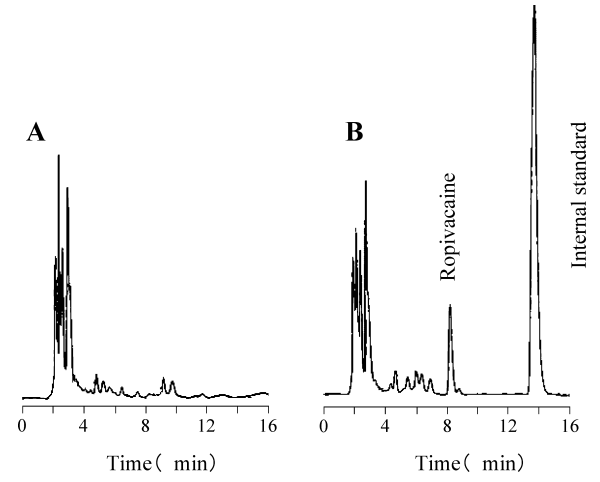

Fig. 2. Typical Chromatograms for Blank Plasma (A) and Plasma Spiked with Ropivacaine $(250 \mathrm{ng} / \mathrm{ml})$ and Internal Standard (B)

Table 1. Recovery of Ropivacaine from Human Plasma

\begin{tabular}{ccc}
\hline \hline & \multicolumn{2}{c}{ Recovery $(n=5)$} \\
\cline { 2 - 3 } $\begin{array}{c}\text { Concentration } \\
(\mathrm{ng} / \mathrm{ml})\end{array}$ & $\begin{array}{c}\text { Mean } \pm \text { S.D. } \\
(\%)\end{array}$ & $\mathrm{CV}$ \\
& $(\%)$ \\
\hline 25 & $87.9 \pm 5.3$ & 6.1 \\
50 & $93.3 \pm 5.2$ & 5.5 \\
250 & $98.8 \pm 5.9$ & 6.0 \\
1000 & $96.7 \pm 2.3$ & 2.4 \\
\hline
\end{tabular}

Table 2. Intra- and Inter-day Precision for the Determination of Plasma Ropivacaine

\begin{tabular}{|c|c|c|c|c|c|c|}
\hline \multirow{2}{*}{$\begin{array}{l}\text { Concentration } \\
(\mathrm{ng} / \mathrm{ml})\end{array}$} & \multicolumn{3}{|c|}{ Intra-day $(n=5)$} & \multicolumn{3}{|c|}{ Inter-day $(n=5)$} \\
\hline & $\begin{array}{l}\text { Mean土S.D. } \\
(\mathrm{ng} / \mathrm{ml})\end{array}$ & $\begin{array}{l}\text { CV } \\
(\%)\end{array}$ & $\begin{array}{l}\text { Bias } \\
(\%)\end{array}$ & $\begin{array}{l}\text { Mean } \pm \text { S.D. } \\
\quad(\mathrm{ng} / \mathrm{ml})\end{array}$ & $\begin{array}{l}\text { CV } \\
(\%)\end{array}$ & $\begin{array}{l}\text { Bias } \\
(\%)\end{array}$ \\
\hline 25 & $25 \pm 3$ & 12.0 & 0 & $27 \pm 4$ & 14.8 & 8.0 \\
\hline 50 & $51 \pm 2$ & 4.0 & 2.0 & $50 \pm 2$ & 4.0 & 0 \\
\hline 250 & $256 \pm 5$ & 2.0 & 2.4 & $254 \pm 8$ & 3.1 & 1.6 \\
\hline 1000 & $1006 \pm 23$ & 2.3 & 0.6 & $1070 \pm 18$ & 1.7 & 7.0 \\
\hline
\end{tabular}

caine in plasma was as low as $25 \mathrm{ng} / \mathrm{ml}$.

The calibration curve for determining plasma ropivacaine was linear at the concentration of $25-1000 \mathrm{ng} / \mathrm{ml}$. The equation of the calibration curve calculated by regression analysis for ropivacaine was $Y=1191.8 X-28.946(r=0.9998)$, where $Y$ was the plasma ropivacaine concentration $(\mathrm{ng} / \mathrm{ml})$ and $X$, the peak height ratio of ropivacaine to IS.

The recoveries of ropivacaine from human plasma examined at concentrations of $25,50,250$ and $1000 \mathrm{ng} / \mathrm{ml}$ were $87.9 \%, 93.3 \%, 98.8 \%$ and $96.7 \%$, respectively, with the coefficient variation (CV) values less than $6.1 \%$ (Table 1). The assay precision of ropivacaine was evaluated by intra- and inter-day validation at the concentrations of 25, 50, 250 and $1000 \mathrm{ng} / \mathrm{ml}$ (Table 2). For intra-day assay precision, 5 sets of each control sample were assayed on the same day. For interday assay precision, 5 sets of each control sample were assayed on 5 different days. The $\mathrm{CV}$ values of the intra- and inter-day assay were $2.0-12.0 \%$ and $1.7-14.8 \%$, respectively. The relative errors (bias) for intra- and inter-day assay were less than 2.4 and $8.0 \%$, respectively.

The method was applied to determining the concentration-time profile for plasma ropivacaine in two healthy vol- 
Table 3. Pharmacokinetic Data of the Volunteers Receiving 0.5\% Ropivacaine Viscous

\begin{tabular}{ccccccccc}
\hline \hline Subject & Sex & $\begin{array}{c}\text { Age } \\
(\text { year })\end{array}$ & $\begin{array}{c}\text { Weight } \\
(\mathrm{kg})\end{array}$ & $\begin{array}{c}C_{\max } \\
(\mathrm{ng} / \mathrm{ml})\end{array}$ & $\begin{array}{c}T_{\max } \\
(\mathrm{min})\end{array}$ & $\begin{array}{c}A U C \\
(\mathrm{ng} \min / \mathrm{ml})\end{array}$ & $\begin{array}{c}t_{1 / 2} \\
(\mathrm{~min})\end{array}$ & $\begin{array}{c}M R T \\
(\mathrm{~min})\end{array}$ \\
\hline A & Male & 48 & 52 & 125 & 60 & 16949 & 63 & 82 \\
B & Male & 24 & 68 & 89 & 40 & 5166 & 39 & 49
\end{tabular}

unteers after applying ropivacaine viscous. The calculated pharmacokinetic parameters of ropivacaine, $C_{\max }, T_{\max }, A U C$, $t_{1 / 2}$ and $M R T$, were listed in Table 3.

\section{DISCUSSION}

Our HPLC method using ethylacetate extraction and ODS column showed a sufficient selectivity and sensitivity for determination of plasma ropivacaine concentration. Solid phase extraction could not be used for pre-treatment of plasma because of the lower recovery rate (less than $80 \%$ ) and several interfering peaks overlapping with ropivacaine. Our chromatographic conditions produced satisfactory separation of ropivacaine and IS from endogenous compounds (Fig. 2) without using column switching technique, which requires optional apparatus for the HPLC system. Also interfering peaks generated from concomitant drugs was not observed on the chromatogram of the plasma samples, which were obtained from patients receiving epidural anesthesia (data not shown). Assay precision of the present method, which was confirmed by the recovery and intra- and inter-day validations, was almost the same as the previous method. ${ }^{12,14,17)}$ The sensitivity was also sufficient to determine plasma ropivacaine in the subjects after receiving $0.5 \%$ ropivacaine viscous. It is considered that present method has an advantage in running cost compared with other methods in terms of the needless any items for sample pre-treatment such as cartridges and pre-column for column switching technique.

Our preliminary results suggest that $0.5 \%$ ropivacaine viscous can be used safely compared with commercially available $2.0 \%$ lidocaine viscous. This hypothesis is supported by previous report that the toxic range of plasma lidocaine concentration on central nervous system was $2152 \mathrm{ng} / \mathrm{ml}$ after administration of viscous preparation. ${ }^{18)}$ The $C_{\max }$ of plasma ropivacaine observed in the present study was 89$125 \mathrm{ng} / \mathrm{ml}$, which was ten times smaller than that of lidocaine. Moreover, the $C_{\max }(89-125 \mathrm{ng} / \mathrm{ml})$ is also lower than the plasma concentration of ropivacaine in previous reports that central nervous toxicity and adverse events of ropivacaine have been seen at the free plasma concentrations of
$600 \mathrm{ng} / \mathrm{ml}^{8)}$ correspond to total plasma concentration of $1700 \mathrm{ng} / \mathrm{ml} .{ }^{19)}$

Individual variation in pharmacokinetic parameters for ropivacaine was observed between two healthy subjects (Table 3), though the blood concentrations were extremely low for assessing systemic activity of this drug. This may be due to difference in absorption of topical ropivacaine on oral mucosa and metabolic activity for systemic ropivacaine.

We need to confirm our preliminary data in healthy subjects with large number of population before assessing the efficacy of this new viscous preparation in clinical trial.

Acknowledgements This study was partly supported by AstraZeneca. We acknowledged Dr. F. Itagaki, Mr. Y. Inoue, Dr. H. Hosono and Mr. K. Doki for their useful technical advices and discussion.

\section{REFERENCES}

1) Olmez G., Cakmak S. S., Caca I., Unlu M. K., Tohoku J. Exp. Med., 204, 203-208 (2004).

2) McClure J. H., Br. J. Anaesth., 76, 300-307 (1996).

3) Nau C., Strichartz G. R., Anesthesiology, 97, 497-502 (2002).

4) Concepcion M., Arthur G. R., Steele S. M., Bader A. M., Covino B. G., Anesth. Analg., 70, 80-85 (1990).

5) Whitehead E., Arrigoni B., Bannister J., Br. J. Anaesth., 64, 67-71 (1990).

6) Scott D. B., Lee A., Fagan D., Bowler G. M. R., Bloomfield P., Lundh R., Anesth. Analg., 69, 563-569 (1989).

7) Plowman A. N., Bolsin S., Mather L. E., Anaesth. Intens. Care, 26, 204-206 (1998).

8) Knudsen K., Suurkula M. B., Blomberg S., Sjovall J., Edvardsson N., Br. J. Anaesth., 78, 507-514 (1997).

9) Keenaghan J. B., Boyes R. N., J. Pharmacol. Exp. Ther, 180, 454463 (1972).

10) Halldin M. M., Bredberg E., Angelin B., Arvidsson T., Askemark Y., Elofsson S., Widman M., Drug Metab. Dispos., 24, 962-968 (1996).

11) Duplay D., "Physicians' Desk Reference," 58th ed., Thomson, New Jersey, 2004.

12) Reif S., Corre P. L., Dollo G., Chevanne F., Verge R. L., J. Chromatogr. B, 719, 239-244 (1998).

13) Arvidsson T., Askemark Y., Halldin M. M., Biomed. Chromatogr., 13, 286-292 (1999)

14) Rifai N., Hsin O., Hope T., Sakamoto M., Ther. Drug Monit., 23, $182-186(2001)$

15) Kau Y. C., Wong K. M., Shry M. H., Lee Y. H., Tsai T. H., J. Chromatogr. B, 760, 107-112 (2001).

16) Arvidsson T., Eklund E., J. Chromatogr. B, 668, 91-98 (1995).

17) Zhang C. Y., Gu J., Duan J. J., Zhong L., Li Y. Z., Chinese J. Chromatogr., 20, 56-58 (2002).

18) Kakiuchi Y., Kohda Y., Sato S., Yamashita S., Sagara E., J. Appl. Ther Res., 2, 157-162 (1998).

19) Emanuelsson B. M., Persson J., Sandin S., Alm C., Gustafsson L. L., Ther. Drug Monit., 19, 126-131 (1997). 